\title{
How to improve obliteration rates during volume-staged stereotactic radiosurgery for large arteriovenous malformations
}

\author{
Hideyuki Kano, MD, PhD, ${ }^{1,3}$ John C. Flickinger, MD, ${ }^{2,3}$ Aya Nakamura, MD, ${ }^{3}$ Rachel C. Jacobs, BS, ${ }^{3}$ \\ Daniel A. Tonetti, MD, ${ }^{1}$ Craig Lehocky, MD, ${ }^{3}$ Kyung-Jae Park, MD, PhD, ${ }^{4}$ Huai-che Yang, MD, ${ }^{5}$ \\ Ajay Niranjan, MCh, MBA, ${ }^{1,3}$ and L. Dade Lunsford, MD ${ }^{1,3}$ \\ Departments of ${ }^{1}$ Neurological Surgery and ${ }^{2}$ Radiation Oncology, and the ${ }^{3} \mathrm{Center}$ for Image-Guided Neurosurgery, University of \\ Pittsburgh School of Medicine, Pittsburgh, Pennsylvania; ${ }^{2}$ Department of Neurosurgery, College of Medicine, Korea University, \\ Seoul, South Korea; and ${ }^{5}$ Department of Neurosurgery, Taipei Veterans General Hospital, Taipei City, Taiwan
}

OBJECTIVE The management of large-volume arteriovenous malformations (AVMs) with stereotactic radiosurgery (SRS) remains challenging. The authors retrospectively tested the hypothesis that AVM obliteration rates can be improved by increasing the percentage volume of an AVM that receives a minimal threshold dose of radiation.

METHODS In 1992, the authors prospectively began to stage anatomical components in order to deliver higher single doses to AVMs $>15 \mathrm{~cm}^{3}$ in volume. Since that time 60 patients with large AVMs have undergone volume-staged SRS (VS-SRS). The median interval between the first stage and the second stage was 4.5 months $(2.8-13.8$ months). The median target volume was $11.6 \mathrm{~cm}^{3}$ (range $4.3-26 \mathrm{~cm}^{3}$ ) in the first-stage SRS and $10.6 \mathrm{~cm}^{3}$ (range $2.8-33.7 \mathrm{~cm}^{3}$ ) in the second-stage SRS. The median margin dose was 16 Gy (range 13-18 Gy) for both SRS stages.

RESULTS AVM obliteration after the initial two staged volumetric SRS treatments was confirmed by MRI alone in 4 patients and by angiography in 11 patients at a median follow-up of 82 months (range 0.4-206 months) after VS-SRS. The post-VS-SRS obliteration rates on angiography were $4 \%$ at 3 years, $13 \%$ at 4 years, $23 \%$ at 5 years, and $27 \%$ at 10 years. In multivariate analysis, only $\geq 20$-Gy volume coverage was significantly associated with higher total obliteration rates confirmed by angiography. When the margin dose is $\geq 17 \mathrm{~Gy}$ and the 20 -Gy SRS volume included $\geq 63 \%$ of the total target volume, the angiographically confirmed obliteration rates increased to $61 \%$ at 5 years and $70 \%$ at 10 years.

CONCLUSIONS The outcomes of prospective VS-SRS for large AVMs can be improved by prescribing an AVM margin dose of $\geq 17$ Gy and adding additional isocenters so that $\geq 63 \%$ of the internal AVM dose receives more than 20 Gy.

https://thejns.org/doi/abs/10.3171/2018.2.JNS172964

KEYWORDS arteriovenous malformation; Gamma Knife; stereotactic radiosurgery; large; stage; vascular disorders

$\mathrm{M}$ ANAGEMENT of large-volume arteriovenous malformations (AVMs) poses significant challenges to patients and physicians. For such AVMs, selected centers began to stage treatment volumes of the AVM using stereotactic radiosurgery (SRS). To date few published reports exist to validate the long-term results of this strategy. ${ }^{13,9,12,18,19}$ The obliteration response of an AVM depends on radiation dose and volume, but for larger volumes, the dose must be reduced to decrease radiationrelated brain injury. In 1992, we began to stage anatomical components of AVMs $\geq 15 \mathrm{~cm}^{3}$ to reduce the risk of adverse radiation effects (AREs) but still deliver a radio- biological dose that would be sufficient to obliterate an AVM. In our previous report, ${ }^{9}$ the 5-year total obliteration rate after the initial two staged volumetric SRS treatments was only $28 \%$. We found that at least a minimal margin dose of $\geq 17$ Gy was needed to improve the 5-year obliteration rate to $62 \%$. We found that $9(24 \%)$ of 47 patients who underwent volume-staged SRS (VS-SRS) died during the latency interval because of incomplete AVM obliteration.

In 2000 Pan et al. ${ }^{13}$ from Taipei suggested that AVM obliteration rates could be improved when a larger intranidal volume received a higher dose, regardless of the margin dose. The present study retrospectively tests that hypothesis.

ABBREVIATIONS ARE = adverse radiation effect; AVM = arteriovenous malformation; SRS = stereotactic radiosurgery; VS-SRS = volume-staged SRS.

SUBMITTED November 25, 2017. ACCEPTED February 22, 2018.

INCLUDE WHEN CITING Published online July 20, 2018; DOI: 10.3171/2018.2.JNS172964. 
TABLE 1. Patient characteristics and radiosurgery parameters

\begin{tabular}{lcc}
\hline \multicolumn{1}{c}{ Characteristic } & No. & $\%$ or Range \\
\hline Sex & & \\
\hline Male & 30 & $50 \%$ \\
\hline Female & 30 & $50 \%$ \\
\hline Median age at 1st-stage SRS (yrs) & 30 & $6-59$ \\
\hline Median interval btwn 1st \& 2nd SRS (mos) & 4.5 & $2.8-13.8$ \\
\hline Location & & \\
\hline Lobar & 43 & $72 \%$ \\
\hline Thalamus & 7 & $12 \%$ \\
\hline Basal ganglia & 7 & $12 \%$ \\
\hline Cerebellum & 3 & $5 \%$ \\
\hline Prior hemorrhage & 26 & $43 \%$ \\
\hline Prior embolization & 26 & $43 \%$ \\
\hline Prior resection & 6 & $10 \%$ \\
\hline SRS as prior treatment & 30 & $50 \%$ \\
\hline Spetzler-Martin grade & & \\
\hline III & 8 & $13 \%$ \\
\hline IV & 22 & $37 \%$ \\
\hline V & 30 & $50 \%$ \\
\hline Vas & &
\end{tabular}

Values are numbers of patients unless otherwise stated.

\section{Methods}

\section{Patient Population}

Sixty patients with large AVMs underwent prospective VS-SRS. There were 30 males and 30 females. The median age at the initial staged SRS was 30 years (range 2.8-13.8 years). Twenty-six patients (43\%) had prior hemorrhages. Six patients (10\%) previously had initial surgical resection of their AVM. Four underwent VS-SRS for a residual nidus (median interval between prior surgery and SRS 5.0 months, range 2.3-8.3 months), and 2 underwent VS-SRS for a recurrent AVM discovered 109 and 221 months after resection. Twenty-six patients (43\%) underwent one or more embolization procedures before SRS. The median interval between the last embolization and VS-SRS was 3.2 months (range 0.7-162 months). The AVMs were located in supratentorial lobar regions in 43 patients $(72 \%)$, the thalamus in $7(12 \%)$, the basal ganglia in 7 (12\%), and the cerebellum in $3(5 \%)$. A SpetzlerMartin grade III AVM was diagnosed in 8 patients (13\%), grade IV in $22(37 \%)$, and grade V in 30 patients $(50 \%)$ (Table 1). ${ }^{20}$ Outcome data were obtained from review of each patient's medical record and supplemented by phone discussions with the patient and/or patient's family and current treating physicians.

\section{Radiosurgery Technique}

Our radiosurgery technique has been described in detail in previous reports. ${ }^{9}$ In brief, using local anesthesia supplemented by intravenous sedation, adult patients underwent application of an imaging-compatible stereotactic head frame. Children underwent the procedure after induction of general endotracheal anesthesia. High-resolution axial MRI was performed and followed by conven- tional or digital subtraction biplane stereotactic angiography at the time of the first procedure. Volumetric 3D dose planning was performed using Leksell GammaPlan software. After outlining the total volume of the AVM nidus on the MR image, a dose plan was created for the entire volume, after which isocenters were gradually subtracted until approximately $50 \%$ of the total volume remained (Fig. 1). The initial volume (often the deepest part) then underwent SRS. The second half volume underwent SRS an average of 4.5 months (range 2.8-13.8 months) later. By the time the second procedure was completed, the margin SRS dose included the entire AVM nidus volume, defined as the shunt between the afferent arteries and draining veins. SRS was performed with either a Model U, B, C, 4-C, or Perfexion Leksell Gamma Knife (Elekta Inc.). The median target volume was $11.6 \mathrm{~cm}^{3}$ (range $4.3-26 \mathrm{~cm}^{3}$ ) in the first stage and $10.6 \mathrm{~cm}^{3}$ (range $2.8-33.7 \mathrm{~cm}^{3}$ ) in the second stage. The median margin dose was 16 Gy (range 13-18 Gy) for both stages (Table 2). All patients received an intravenous dose of 20-40 mg methylprednisolone after radiosurgery, and all were discharged from the hospital 2-24 hours after the procedure. Anticonvulsant medications were administered to all patients with supratentorial lobar AVMs and were continued long term in patients with a history of seizures.

\section{Patient Follow-Up}

After radiosurgery, the patients were requested to have clinical and imaging assessments at 6-, 12-, 24-, and 36-month intervals. If at the end of 3 years MRI suggested complete AVM obliteration, then a repeat angiogram was requested. If the MRI clearly defined a residual nidus, angiography was delayed, and the patient was offered repeat radiosurgery to further increase the likelihood of complete obliteration.

In this study patients who underwent additional management after SRS (e.g., post-VS-SRS embolization, repeat SRS after VS-SRS, and resection after VS-SRS) were censored by the date of additional surgical management. This study was focused on the results of the initial VS-SRS.

Total AVM obliteration, as defined using MRI, reflected disappearance of the nidus on enhanced T1- and T2weighted images and the disappearance of flow voids on T2-weighted images. Total AVM obliteration was determined after imaging review at a multidisciplinary conference supplemented by the radiology interpretation. Total angiographic AVM obliteration was defined as disappearance of the nidus and absence of early venous drainage. At any time when a new neurological symptom or sign developed, the patient underwent CT scanning and/or MRI to rule out a hemorrhage or AREs. This retrospective analysis was approved by the University of Pittsburgh Institutional Review Board.

\section{Statistical Analysis}

We retrospectively evaluated target volume, the 12Gy volume, the $18-$ Gy volume, and the $20-$ Gy volume for each stage (Table 2). Subsequently all data were summed up into total target volume (target volume on stage 1 plus 

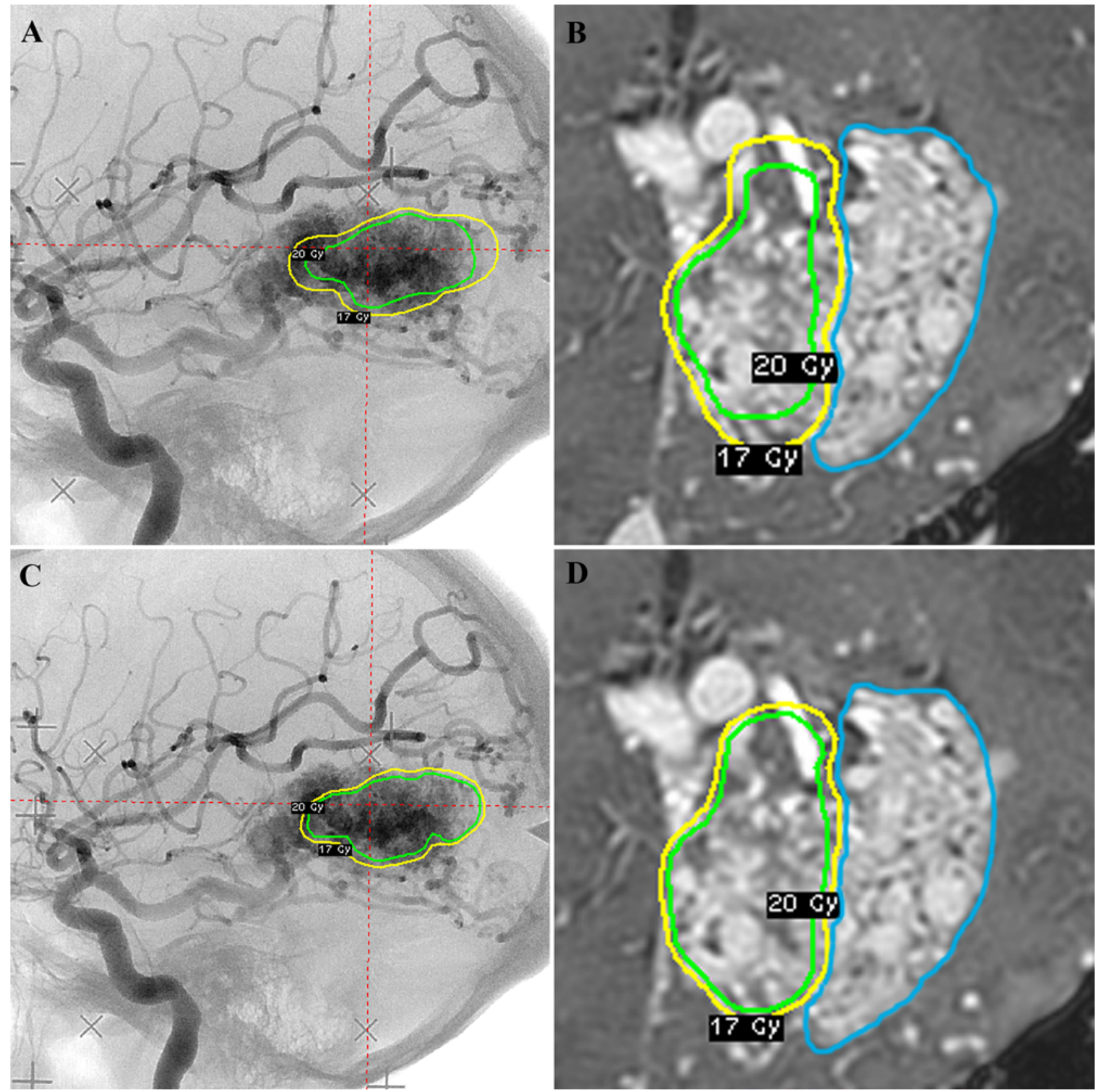

FIG. 1. A: Original first-stage SRS planning using GammaPlan version 10 for a large left occipital AVM. Lateral angiogram. B: Axial T1-weighted MR image: $7 \times 8-\mathrm{mm}$ isocenters, target volume $10.1 \mathrm{~cm}^{3}, 20-$ Gy volume $5.7 \mathrm{~cm}^{3}, 20$-Gy volume rate $56 \%$, and 12-Gy volume $18.1 \mathrm{~cm}^{3}$. Yellow outer line: 17-Gy line. Green inner line: 20-Gy line. Blue line: second-stage target. C: Simulated first-stage SRS planning. Lateral angiogram. D: Axial T1-weighted MR image; $20 \times 4-\mathrm{mm}$ isocenters, target volume $10.0 \mathrm{~cm}^{3}$, 20 -Gy volume $7.1 \mathrm{~cm}^{3}, 20-$ Gy volume rate $71 \%$, and $12-$ Gy volume $16.0 \mathrm{~cm}^{3}$. Yellow outer line: $17-G y$ line. Green inner line: $20-G y$ line. Blue line: second-stage target. Multiple low-weighted additional isocenters placed within the volume described by $17 \mathrm{~Gy}$ can significantly increase the volume of the AVM receiving $\geq 20 \mathrm{~Gy}$. Figure is available in color online only.

target volume on stage 2), total 12-Gy volume (12-Gy volume on stage 1 plus 12-Gy volume on stage 2), total 18-Gy volume (18-Gy volume on stage 1 plus 18 -Gy volume on stage 2 ), and total $20-$ Gy volume (20-Gy volume on stage 1 plus 20-Gy volume on stage 2). The data of 12-Gy volume, 18-Gy volume, and 20-Gy volume are shown in the Table 2. Subsequently we calculated the total (summation of the first and second stage) 18-Gy coverage rate (total 18-
Gy volume/total target volume); the total $20-$ Gy coverage rate (total 20-Gy volume/total target volume); the 18-Gy volume coverage rate of $\geq 70 \%, \geq 75 \%$, and $\geq 80 \%$; and the 20 -Gy volume coverage rate of $\geq 50 \%, \geq 60 \%$, and $\geq 63 \%$.

For statistical analysis we constructed Kaplan-Meier plots for total AVM obliteration on MRI or angiography, total AVM obliteration on angiography, and symptomatic AREs using the dates of the second staged SRS, follow-up 
TABLE 2. VS-STS parameters

\begin{tabular}{lcccccc}
\hline \multirow{2}{*}{ Parameter } & \multicolumn{2}{c}{ 1st-Stage SRS } & & \multicolumn{2}{c}{ 2nd-Stage SRS } \\
\cline { 2 - 3 } \cline { 5 - 6 } & Median & Range & & Median & Range \\
\hline Target volume $\left(\mathrm{cm}^{3}\right)$ & 11.6 & $4.3-26.0$ & & 10.6 & $2.8-33.7$ \\
\hline Margin dose $(\mathrm{Gy})$ & 16 & $14-18$ & & 16 & $13-18$ \\
\hline Maximum dose $(\mathrm{Gy})$ & 32 & $27.3-36$ & & 32 & $26-36$ \\
\hline Isocenters $(\mathrm{no})$ & 7 & $3-16$ & & 7 & $1-14$ \\
\hline 12-Gy volume $\left(\mathrm{cm}^{3}\right)$ & 19.6 & $7.0-38.7$ & & 17.7 & $3.6-46.1$ \\
\hline 18-Gy volume $\left(\mathrm{cm}^{3}\right)$ & 9.3 & $2.9-15.8$ & & 8.7 & $1.9-22.8$ \\
\hline 20-Gy volume $\left(\mathrm{cm}^{3}\right)$ & 6.7 & $1.6-12.3$ & & 5.3 & $0.9-16.7$ \\
\hline 24-Gy volume $\left(\mathrm{cm}^{3}\right)$ & 2.2 & $0.4-6.8$ & & 1.9 & $0.1-6.6$ \\
\hline
\end{tabular}

MR images or angiography, symptomatic AREs, additional SRS, and death or last follow-up. Univariate analysis was performed on the Kaplan-Meier curves using log-rank statistics, with $\mathrm{p}<0.05$ set as significant. We performed multivariate analysis using the Cox proportional hazards model, with $\mathrm{p}<0.05$ set as significant. The suggested cutoff value for variables (including dose, 18-Gy volume, and 20-Gy volume) were determined by the Youden index based on receiver operating characteristic curve analysis. Standard statistical processing software (SPSS, version 22.0; IBM Corp.) was used.

\section{Results \\ Obliteration Rates After SRS}

AVM obliteration after the initial two staged volumetric SRS treatments was confirmed by MRI alone in 4 patients and by angiography in 11 patients at a median follow-up of 82 months (range 0.4-206 months). The postVS-SRS obliteration rates on MRI or angiography were $6 \%$ at 3 years, $15 \%$ at 4 years, $25 \%$ at 5 years, and $44 \%$ at 10 years (Fig. 2). The post-VS-SRS obliteration rates on angiography were $4 \%$ at 3 years, $13 \%$ at 4 years, $23 \%$ at 5 years, and $27 \%$ at 10 years (Fig. 2). In the univariate analysis, factors associated with a higher rate of total obliteration on angiography after the initial two-staged volumetric SRS included a higher margin dose (continuous number $\geq 18 \mathrm{~Gy}, \geq 17 \mathrm{~Gy}$, and $\geq 16 \mathrm{~Gy}$ ), higher 18-Gy volume coverage (continuous percentage $\geq 70 \%, \geq 75 \%$, and $\geq 80 \%$ ), higher 20 -Gy volume coverage (continuous percentage $\geq 50 \%, \geq 60 \%$, and $\geq 63 \%$ ), prior resection, and lower Spetzler-Martin grade (Table 3). In the multivariate analysis, only higher intranidal $20-$ Gy volume coverage rate was significantly associated with a higher total obliteration rate on angiography (Table 4).

The relationship between margin dose, total target volume, and 20-Gy volume coverage is shown in Table 5. The cutoff value for total obliteration that maximized the Youden index was $17 \mathrm{~Gy}$ for the margin dose with sensitivity of 0.818 and specificity of $0.612 ; 80 \%$ for $18-\mathrm{Gy}$ volume coverage with a sensitivity of 0.818 and specificity of 0.592 ; and $63 \%$ for 20 -Gy volume coverage with sensitivity of 0.818 and specificity of 0.694 .

The post-VS-SRS obliteration rates on angiography in patients who received $\geq 17$-Gy margin doses were $5 \%$ at 3 years, $24 \%$ at 4 years, $43 \%$ at 5 years, and $51 \%$ at 10 years.
In contrast the post-VS-SRS obliteration rates on angiography in patients who received < 17-Gy margin dose were $4 \%$ at 3 years, $4 \%$ at 4 years, $8 \%$ at 5 years, and $8 \%$ at 10 years (Fig. 2). A margin dose of $\geq 17$ Gy was significantly associated with a higher total obliteration rate on angiography $(\mathrm{p}=0.003)$.

The post-VS-SRS obliteration rates on angiography when the 20 -Gy volume included $\geq 63 \%$ of the total target volume were $7 \%$ at 3 years, $37 \%$ at 4 years, $61 \%$ at 5 years, and $70 \%$ at 10 years. The median time to total obliteration on angiography was 49.1 months after VS-SRS. The VS-SRS angiographic obliteration rates when the 20-Gy volume included $<63 \%$ of the total target volume were $3 \%$ at 3 years, $3 \%$ at 4 years, $7 \%$ at 5 years, and $7 \%$ at 10 years (Fig. 2). When $\geq 63 \%$ of the AVM volume received $\geq 20$ Gy, a significantly higher obliteration rate at 10 years was achieved $(\mathrm{p}<0.0001)$.

For 30 patients who underwent SRS as their primary procedure, the cutoff value for total obliteration that maximized the Youden index was $63 \%$ for the $20-$ Gy volume coverage with sensitivity of 1.000 and specificity of 0.760 . Nineteen patients who underwent primary SRS had 20Gy volume coverage $<63 \%$ and 11 patients had $\geq 63 \%$ of the total target volume. Five of 11 patients with $20-G y$ volume coverage $\geq 63 \%$ had total obliteration on angiography after VS-SRS, while no patients with 20-Gy volume coverage $<63 \%$ had total obliteration. In the group of patients who underwent primary SRS, the post-VS-SRS obliteration rates on angiography (when the 20 -Gy volume covered $\geq 63 \%$ of total target volume) were $33 \%$ at 4 years and $56 \%$ at 5 years (Fig. 3). The VS-SRS angiographic obliteration rate (when the $20-$ Gy volume covered $<63 \%$ of total target volume) was $0 \%$ at 5 years. Patients who underwent primary VS-SRS and whose 20-Gy AVM coverage rate was $\geq 63 \%$ achieved a higher rate of total angiographically confirmed obliteration $(\mathrm{p}=0.003)$.

\section{Hemorrhage After Staged Radiosurgery}

At the time of this assessment, 51 patients were alive, 14 patients had bleeds but survived, and 9 patients had died of AVM hemorrhage. The cumulative rates of AVM hemorrhage after VS-SRS were $1.7 \%$ at 1 year, $5.2 \%$ at 2 years, $7.0 \%$ at 3 years, $9.0 \%$ at 5 years, and $25.2 \%$ at 10 years. The rate of fatal hemorrhage after VS-SRS was $1.7 \%$ at 1 year, $5.2 \%$ at 2 years, $5.2 \%$ at 3 years, $7.2 \%$ at 5 years, and $16.7 \%$ at 10 years. We found no specific factors that were associated with an increased hemorrhage risk after VS-SRS (Table 3).

\section{Adverse Radiation Effects}

One patient developed transient but symptomatic ARE (hemiparesis) 3 months after the first-stage SRS for a parietal AVM with an initial volume of $8.7 \mathrm{~cm}^{2}$ and a margin dose of $18 \mathrm{~Gy}$, This patient did not develop additional AREs after the second stage. Four additional patients (7\%) with AVMs in functional regions of the brain such as the motor or visual cortex developed symptomatic AREs at 6-12 months after the second-stage SRS. No patients developed a delayed cyst formation or a radiation-related neoplasm during the follow-up interval. 

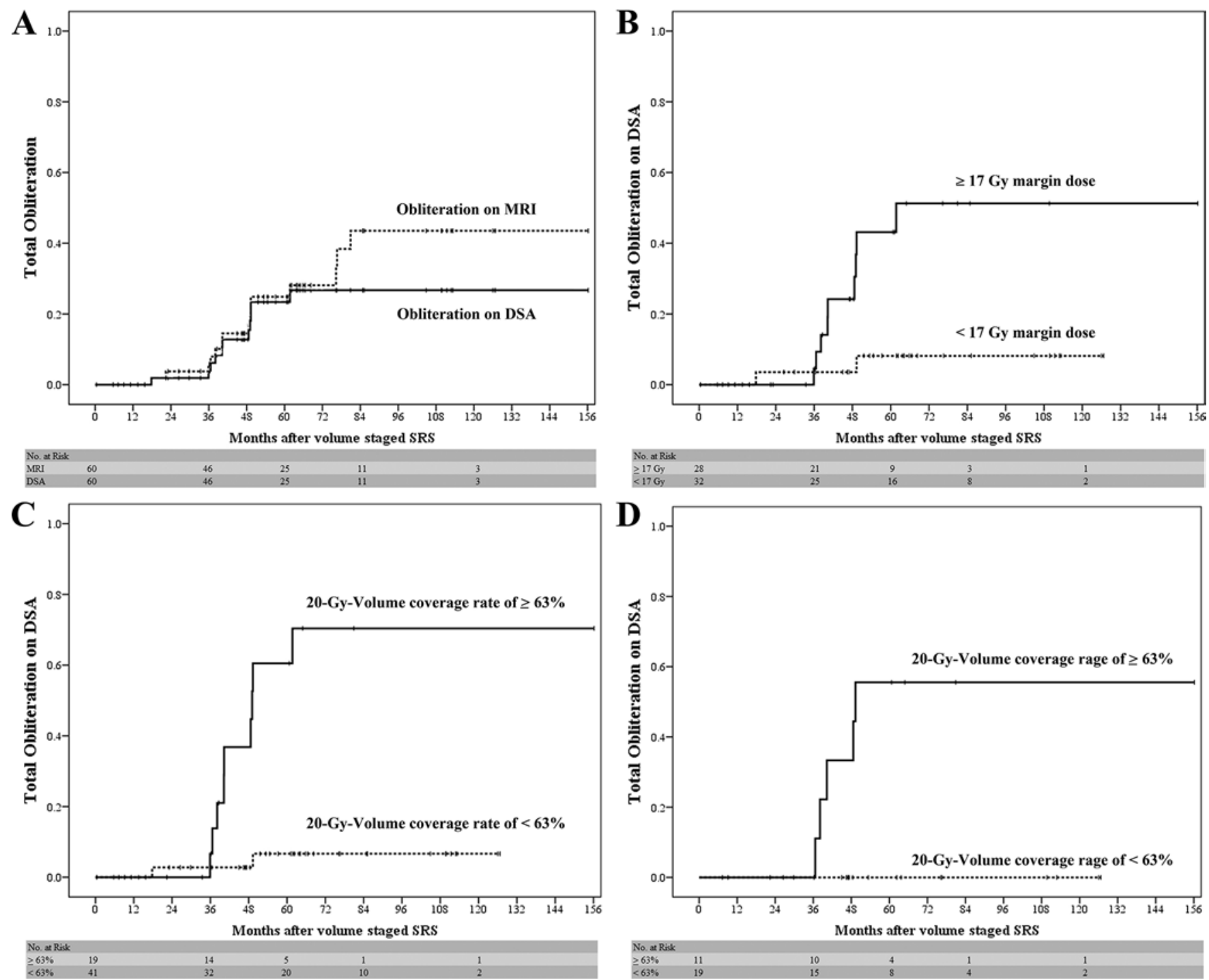

FIG. 2. A: Kaplan-Meier curve for total obliteration on MRI or angiography after VS-SRS for large AVMs. B: Kaplan-Meier curve for total obliteration on angiography after VS-SRS for large AVMs with a margin dose of $\geq 17$ Gy vs < 17 Gy. C: Kaplan-Meier curve for total obliteration on angiography after VS-SRS for large AVMs with the 20 -Gy volume rate of $\geq 63 \%$ vs $<63 \%$ of the total target volume. D: In patients who underwent SRS as a primary treatment, Kaplan-Meier curve for total obliteration on angiography after VS-SRS for large AVMs with the 20 -Gy volume rate of $\geq 63 \%$ vs $<63 \%$ of the total target volume.

\section{Discussion}

The obliteration response of an AVM is dependent on radiation dose and volume; for larger volumes, the dose must be reduced to lessen the risk of an ARE. Such a dose reduction, however, significantly reduces the likelihood of successful AVM obliteration, which is needed to prevent subsequent brain hemorrhage. Larger-volume AVMs also increase the difficulty in accurately defining the nidal target, especially when angiopathic changes or a diffuse nidus is defined by imaging. Prior embolization may also obscure the final target volume and may reduce the ultimate successful obliteration rate. ${ }^{8}$ Prospective VS-SRS for large-volume AVMs has been described as a potentially effective treatment strategy for otherwise incurable symptomatic AVMs. Volume staging is designed to improve the obliteration rate while maintaining a reasonable safety profile. In 2000 Pan et al., ${ }^{13}$ working at Taipei Veterans General hospital, began to advocate increasing the intranidal dose delivered to the AVM without changing the margin dose. This can be done by adding low-weighted isocenters within the treatment volume, with the goal of increasing the percentage of volume that receives a higher radiation dose. The present study examined the outcomes of our patients who underwent an initial staged SRS procedure. We retrospectively evaluated these patients to determine if an increased volume of AVM receiving $>20 \mathrm{~Gy}$ was associated with improved obliteration rates.

\section{Background}

Stereotactic radiosurgery is an effective option for small- to medium-volume AVMs. Successful obliteration has been found to be dose dependent. Hattangadi et al. ${ }^{4}$ 
TABLE 3. Univariate analysis of total obliteration and bleeding after VS-SRS in 60 patients

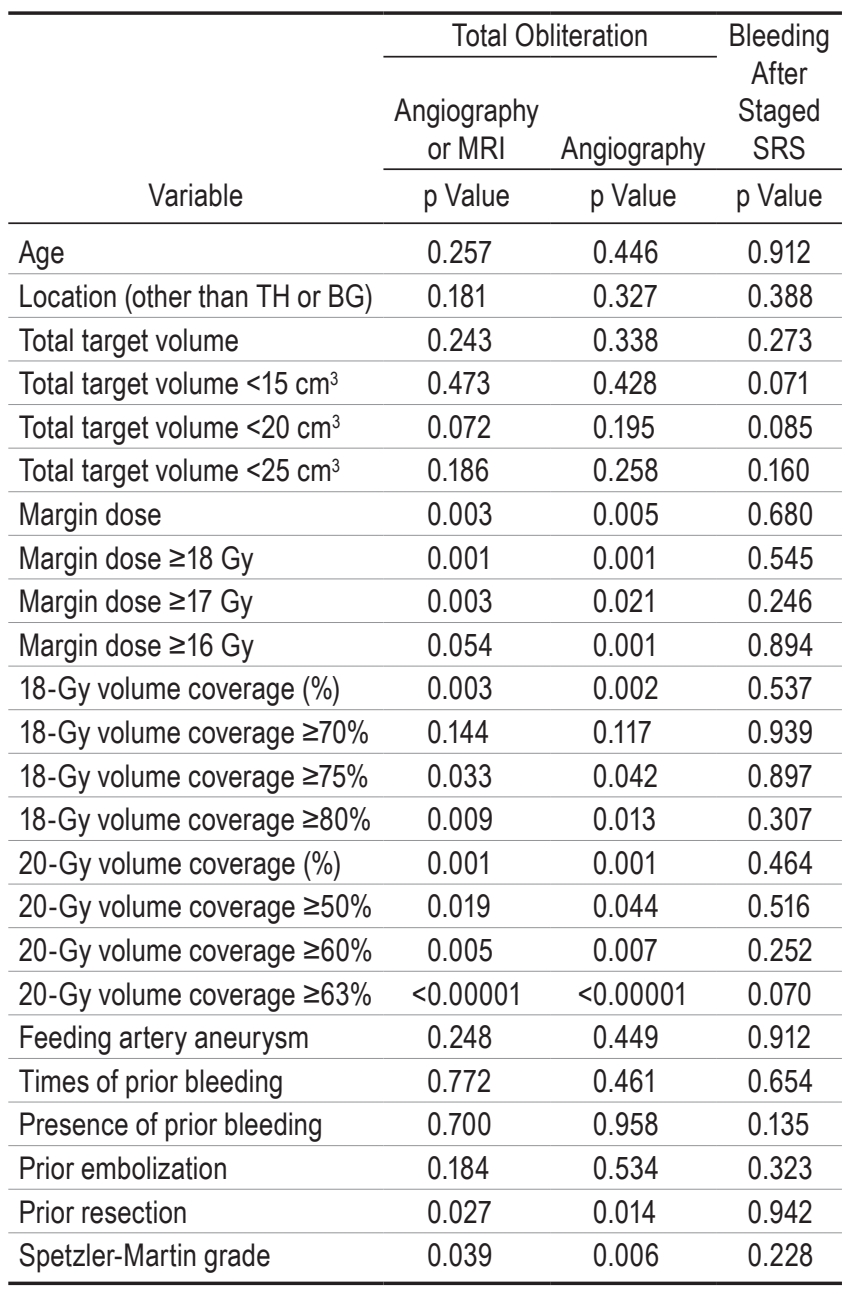

$\mathrm{BG}=$ basal ganglia; $\mathrm{TH}=$ thalamus .

reported a $15 \%$ overall obliteration rate after two-fraction proton SRS for large AVMs with a median target volume of $22.9 \mathrm{~cm}^{2}$. Conventional fractionated radiotherapy has
TABLE 5. Relationship between margin dose and volume coverage

\begin{tabular}{lccc}
\hline Margin Dose & No. & $\begin{array}{c}\text { Median Total Target Vol } \\
\text { (range) }\end{array}$ & $\begin{array}{c}\text { Median 20-Gy Vol } \\
\text { Coverage (range) }\end{array}$ \\
\hline$<15 \mathrm{~Gy}$ & 17 & $29.5 \mathrm{~cm}^{3}\left(14.3-56.9 \mathrm{~cm}^{3}\right)$ & $39 \%(23.6 \%-47.1 \%)$ \\
\hline $16 \mathrm{~Gy}$ & 15 & $25.0 \mathrm{~cm}^{3}\left(11.7-48.3 \mathrm{~cm}^{3}\right)$ & $54 \%(45.8 \%-57.8 \%)$ \\
\hline $17 \mathrm{~Gy}$ & 16 & $17.5 \mathrm{~cm}^{3}\left(10.2-35.8 \mathrm{~cm}^{3}\right)$ & $63 \%(57.9 \%-68.1 \%)$ \\
\hline $17.5-18 \mathrm{~Gy}$ & 12 & $18.3 \mathrm{~cm}^{3}\left(10.9-31.4 \mathrm{~cm}^{3}\right)$ & $79 \%(69.0 \%-83.6 \%)$ \\
\hline
\end{tabular}

had limited benefit for large-volume AVMs. ${ }^{17}$ Prior experience with single-staged SRS of large-volume AVMs was associated with a either a low rate of obliteration or a high rate of AREs. Patibandla et al. ${ }^{14}$ reported a series of patients with Spetzler-Martin grade IV-V AVMs who underwent single-session SRS. The total obliteration rates on MRI or angiography were $15 \%$ at 3 years, $34 \%$ at 7 years, and $37 \%$ at 10 years. Symptomatic ARE was found in $14 \%$ of the patients. Because of such reported higher obliteration rates with reduced complications, Ilyas et al. ${ }^{6}$ reported that VS-SRS was a potentially superior approach to dose staging (or fractionated SRS). Our recent review of the outcomes of prospective volume-staged radiosurgery indicates that obliteration can be documented in approximately $50 \%$ of patients by 10 years. ${ }^{9}$ During the latency interval, bleeding risks remain and it may approach 50\% of patients whose AVM fails to obliterate. ${ }^{9}$ Prior to SRS, AVM embolization has been advocated despite its limited curative potential and associated additional management morbidity. We have found that pre-SRS embolization often leads to AVM flow reduction but not to significant AVM volume reduction. We previously reported that prior embolization reduced the rate of total obliteration after SRS and provided no reduction in the latency interval hemorrhage. ${ }^{8}$

\section{Can We Improve AVM Obliteration Rates After VS-SRS?}

We previously reported that the 5-year total obliteration rate $(62 \%)$ was significantly better in patients who received a margin dose of $\geq 17$ Gy compared to $<17$ Gy $(4 \%)$.

TABLE 4. Multivariate analysis of total obliteration after VS-SRS in 60 patients

\begin{tabular}{|c|c|c|c|c|c|c|}
\hline \multirow[b]{3}{*}{ Variable } & \multicolumn{6}{|c|}{ Total Obliteration } \\
\hline & \multicolumn{3}{|c|}{ Angiography or MRI } & \multicolumn{3}{|c|}{ Angiography } \\
\hline & p Value & $H R$ & $95 \% \mathrm{Cl}$ & $p$ Value & $\mathrm{HR}$ & $95 \% \mathrm{Cl}$ \\
\hline Age & 0.272 & NA & NA & 0.467 & NA & NA \\
\hline Location (other than TH or BG) & 0.557 & NA & NA & 0.278 & NA & NA \\
\hline Total target volume & 0.764 & NA & NA & 0.874 & NA & NA \\
\hline Margin dose & 0.646 & NA & NA & 0.778 & NA & NA \\
\hline 18-Gy volume coverage (\%) & 0.994 & NA & NA & 0.570 & NA & NA \\
\hline 20-Gy volume coverage (\%) & 0.001 & 1.086 & $1.036-1.138$ & 0.001 & 1.095 & $1.037-1.158$ \\
\hline Prior embolization & 0.636 & NA & NA & 0.665 & NA & NA \\
\hline Prior surgical resection & 0.763 & NA & NA & 0.687 & NA & NA \\
\hline Spetzler-Martin grade & 0.401 & NA & NA & 0.114 & NA & NA \\
\hline
\end{tabular}

$\mathrm{NA}=$ not applicable 
Seymour et al. ${ }^{18}$ also reported that a margin dose of $\geq 17$ Gy was associated with double the rate of at least a partial response. They also reported that prior embolization was a negative predictor of complete or near-complete obliteration. They concluded that decreasing the AVM treatment volume per stage allowed a higher dose per fraction and decreased time to response, as well as improved rates of near-total obliteration without increasing complications. Pollock et al. ${ }^{15}$ also reported that 4 of 5 patients who underwent VS-SRS using a smaller volume per stage with a higher dose had excellent outcomes. In the present study, we found that the volume of the AVM that received $\geq 20 \mathrm{~Gy}$ was the best predictor of total obliteration after VS-SRS in the multivariate analysis $(\mathrm{p}<0.0001, \mathrm{HR}=17.17,95 \% \mathrm{CI}$ 4.56-64.63). The cutoff value for $20-$ Gy volume coverage was $63 \%$, a value that maximized the Youden index in the entire series and in patients who underwent SRS as primary treatment. In the group of patients who underwent SRS and received at least 20 Gy to $>63 \%$ of the total target volume the 5-year post-angiographic obliteration rate was $56 \%$. In comparison the 5-year angiographic obliteration rates when the $20-$ Gy volume included $<63 \%$ of the total target volume was $0 \%$. Optimization of the radiosurgical planning is important to improve the total obliteration rate. Multiple low-weighted additional isocenters placed within the volume described by 17 Gy can significantly increase the volume of the AVM receiving $\geq 20$ Gy (Fig. 1). The use of multiple small isocenters increases the 20 -Gy volume compared to the use of a smaller number of large isocenters. Figure 1 shows that the use of seven 8-mm isocenters results in 56\% of the AVM receiving at least 20 Gy (Fig. $1 \mathrm{~A}$ and $\mathrm{B}$ ) whereas twenty $4-\mathrm{mm}$ isocenters increases the minimum 20-Gy volume to $71 \%$ (Fig. 1C and D).

\section{Hemorrhage After VS-SRS}

Seymour et al. ${ }^{18}$ reported that $7(22.6 \%)$ of 33 patients with large-volume AVMs had latency interval hemorrhages and $4(12.9 \%)$ died. Hanakita et al. ${ }^{3}$ reported that $4(22.2 \%)$ of 18 patients who underwent VS-SRS for large AVMs had hemorrhages and 1 patient (5.6\%) died. In the present study, 14 (23.3\%) of 60 patients had latency interval hemorrhages, and $9(15 \%)$ died. The median time to total obliteration defined by angiography was 49.1 months in patients who underwent SRS as a primary treatment and whose $20-$ Gy volume coverage exceeded $\geq 63 \%$. Because of the high morbidity and mortality rates associated with symptomatic large-volume AVMs, we believe that a strategy of increasing the percentage of the AVM volume receiving a high dose may reduce the delayed hemorrhage and mortality rate by increasing the obliteration rate.

\section{AREs After VS-SRS}

The risk of AREs resulting in a permanent neurological deficit is $2 \%$ to $3 \%$ in most reports after single-session AVM SRS..$^{10,11,16}$ We previously reported that the rates of developing permanent symptomatic AREs in single-session SRS were higher in the brainstem (11\%) and thalamus AVMs (7\%), compared to AVMs located in other brain locations $(0 \%-3 \%){ }^{7}$ In their multicenter study, CohenInbar et al. reported that the rate of symptomatic AREs was $14.6 \%$ in patients with brainstem AVMs who under-
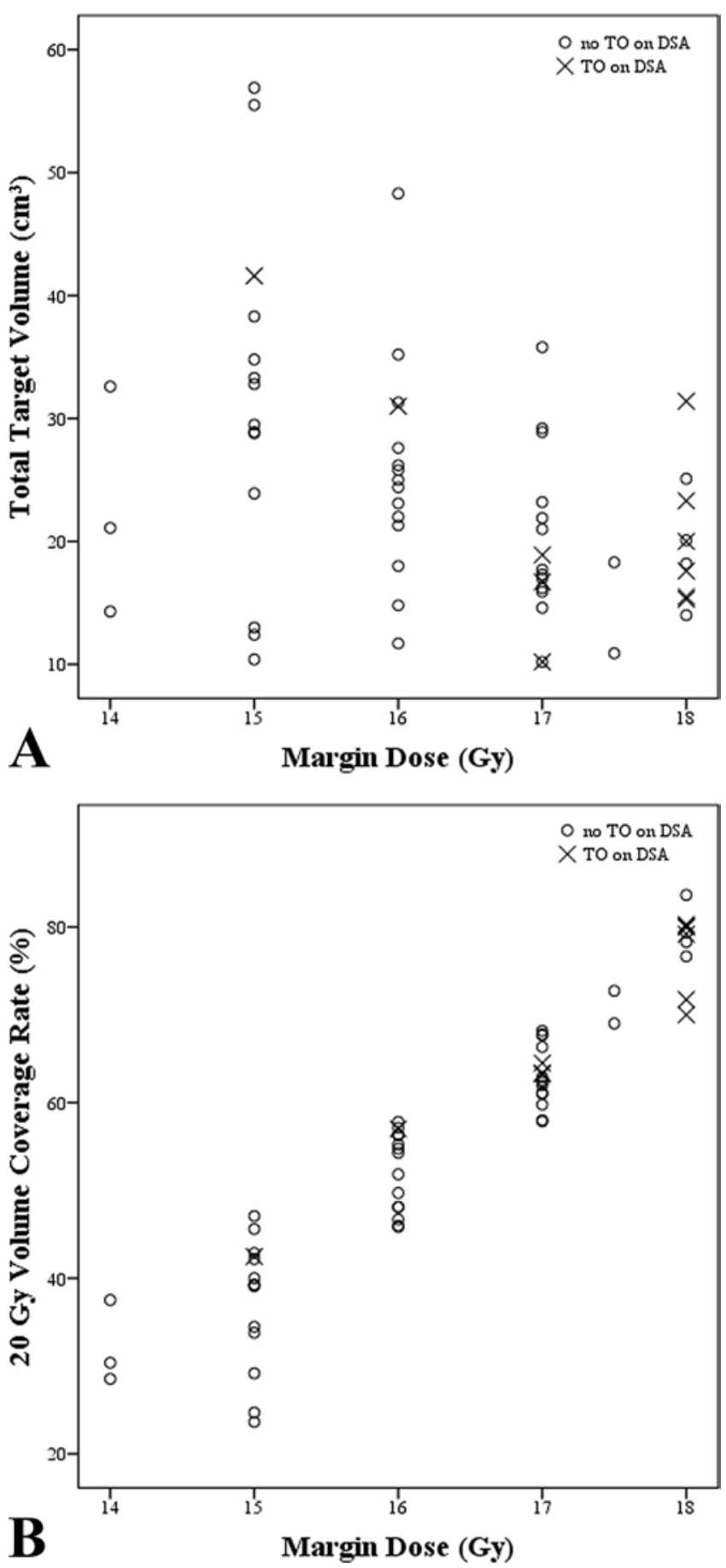

FIG. 3. A: Scatter plot illustrating the relationship between total target volume and margin dose, with total obliteration on angiography versus no total obliteration on angiography. B: Scatter plot illustrating the relationship between $20-G y$ volume coverage and margin dose, with total obliteration on angiography versus no total obliteration on angiography. DSA = digital subtraction angiography; $\mathrm{TO}=$ total obliteration.

went single-session SRS. ${ }^{2}$ The reported rates of symptomatic AREs after VS-SRS has varied between $3 \%$ and 7\%. ${ }^{5,9,12,15,18}$ In the present study, 2 patients (3\%) had temporary symptomatic AREs and 2 patients (3\%) had irreversible symptomatic AREs after VS-SRS. 


\section{Study Limitations}

The present study is a retrospective outcome analysis. Some patients underwent prior resection and/or prior embolization. Because this subgroup is subject to selection bias, we independently analyzed 30 patients who underwent primary VS-SRS. We found no difference in outcomes.

\section{Conclusions}

During our 30-year experience, an increasing understanding of dose-volume relationships, the importance of conformal and selective dose planning, and improved outcome analyses gradually expanded our knowledge related to the care of patients with large-volume AVMs. In this study, we found that the final obliteration rate can be increased if $\geq 63 \%$ of the volume receives $\geq 20$ Gy. In addition to prescribing a minimal margin dose of $17 \mathrm{~Gy}$ to large-volume AVMS treated in two stages, we now add additional intranidal isocenters to increase the percentage of the AVM volume that receives at least 20 Gy.

\section{Acknowledgments}

The work described in this report was funded by a research grant to Dr. Kano from AB Elekta, Stockholm, Sweden.

\section{References}

1. Chung WY, Shiau CY, Wu HM, Liu KD, Guo WY, Wang LW, et al: Staged radiosurgery for extra-large cerebral arteriovenous malformations: method, implementation, and results. J Neurosurg 109 Suppl:65-72, 2008

2. Cohen-Inbar O, Starke RM, Lee CC, Kano H, Huang P, Kondziolka D, et al: Stereotactic radiosurgery for brainstem arteriovenous malformations: a multicenter study. Neurosurgery 81:910-920, 2017

3. Hanakita S, Shin M, Koga T, Igaki H, Saito N: Outcomes of volume-staged radiosurgery for cerebral arteriovenous malformations larger than $20 \mathrm{~cm}^{3}$ with more than 3 years of follow-up. World Neurosurg 87:242-249, 2016

4. Hattangadi JA, Chapman PH, Bussière MR, Niemierko A, Ogilvy CS, Rowell A, et al: Planned two-fraction proton beam stereotactic radiosurgery for high-risk inoperable cerebral arteriovenous malformations. Int J Radiat Oncol Biol Phys 83:533-541, 2012

5. Huang PP, Rush SC, Donahue B, Narayana A, Becske T, Nelson PK, et al: Long-term outcomes after staged-volume stereotactic radiosurgery for large arteriovenous malformations. Neurosurgery 71:632-644, 2012

6. Ilyas A, Chen CJ, Ding D, Taylor DG, Moosa S, Lee CC, et al: Volume-staged versus dose-staged stereotactic radiosurgery outcomes for large brain arteriovenous malformations: a systematic review. J Neurosurg 128:154-164, 2018

7. Kano H, Flickinger JC, Tonetti D, Hsu A, Yang HC, Flannery TJ, et al: Estimating the risks of adverse radiation effects after Gamma Knife radiosurgery for arteriovenous malformations. Stroke 48:84-90, 2017

8. Kano H, Kondziolka D, Flickinger JC, Park KJ, Iyer A, Yang $\mathrm{HC}$, et al: Stereotactic radiosurgery for arteriovenous malformations after embolization: a case-control study. J Neurosurg 117:265-275, 2012

9. Kano H, Kondziolka D, Flickinger JC, Park KJ, Parry PV, Yang HC, et al: Stereotactic radiosurgery for arteriovenous malformations, Part 6: multistaged volumetric management of large arteriovenous malformations. J Neurosurg 116:5465,2012

10. Liscák R, Vladyka V, Simonová G, Urgosík D, Novotný J Jr, Janousková L, et al: Arteriovenous malformations after Leksell gamma knife radiosurgery: rate of obliteration and complications. Neurosurgery 60:1005-1016, 2007

11. Lunsford LD, Kondziolka D, Flickinger JC, Bissonette DJ, Jungreis CA, Maitz AH, et al: Stereotactic radiosurgery for arteriovenous malformations of the brain. J Neurosurg 75:512-524, 1991

12. Nagy G, Grainger A, Hodgson TJ, Rowe JG, Coley SC, Kemeny AA, et al: Staged-volume radiosurgery of large arteriovenous malformations improves outcome by reducing the rate of adverse radiation effects. Neurosurgery 80:180-192, 2017

13. Pan DH, Guo WY, Chung WY, Shiau CY, Chang YC, Wang LW: Gamma knife radiosurgery as a single treatment modality for large cerebral arteriovenous malformations. J Neurosurg 93 (Suppl 3):113-119, 2000

14. Patibandla MR, Ding D, Kano H, Xu Z, Lee JYK, Mathieu $\mathrm{D}$, et al: Stereotactic radiosurgery for Spetzler-Martin Grade IV and V arteriovenous malformations: an international multicenter study. J Neurosurg [epub ahead of print September 8, 2017; DOI: 10.3171/2017.3.JNS162635]

15. Pollock BE, Link MJ, Stafford SL, Lanzino G, Garces YI, Foote RL: Volume-staged stereotactic radiosurgery for intracranial arteriovenous malformations: outcomes based on an 18-year experience. Neurosurgery 80:543-550, 2017

16. Pollock BE, Meyer FB: Radiosurgery for arteriovenous malformations. J Neurosurg 101:390-392, 2004

17. Redekop GJ, Elisevich KV, Gaspar LE, Wiese KP, Drake CG Conventional radiation therapy of intracranial arteriovenous malformations: long-term results. J Neurosurg 78:413-422, 1993

18. Seymour ZA, Sneed PK, Gupta N, Lawton MT, Molinaro AM, Young W, et al: Volume-staged radiosurgery for large arteriovenous malformations: an evolving paradigm. J Neurosurg 124:163-174, 2016

19. Sirin S, Kondziolka D, Niranjan A, Flickinger JC, Maitz AH, Lunsford LD: Prospective staged volume radiosurgery for large arteriovenous malformations: indications and outcomes in otherwise untreatable patients. Neurosurgery 58:17-27, 2006

20. Spetzler RF, Martin NA: A proposed grading system for arteriovenous malformations. J Neurosurg 65:476-483, 1986

\section{Disclosures}

Dr. Lunsford is an Elekta AB stockholder and is a consultant for INSIGHTEC. The work described in this report was funded by a research grant to Dr. Kano from AB Elekta, Stockholm, Sweden.

\section{Author Contributions}

Conception and design: Kano. Acquisition of data: Kano, Nakamura, Jacobs, Tonetti, Lehocky, Park, Yang. Analysis and interpretation of data: Kano. Drafting the article: Kano, Flickinger. Critically revising the article: Kano, Flickinger, Lunsford. Reviewed submitted version of manuscript: all authors. Approved the final version of the manuscript on behalf of all authors: Kano. Statistical analysis: Kano. Study supervision: Kano.

\section{Correspondence}

Hideyuki Kano: University of Pittsburgh School of Medicine, Pittsburgh,PA.kanoh@upmc.edu. 